\title{
AHP BASED DECISION MODEL FOR APPRAISING RESIDENTIAL REAL ESTATES IN AN ABSTRACTED ZONE
}

\author{
Seçil Kavas, Y. Ilker Topçu \\ Istanbul Technical University, Industrial Engineering Department, \\ Maçka Campus 34357, Maçka, Turkey \\ E-mail: kavas@itu.edu.tr, topcuil@itu.edu.tr
}

\begin{abstract}
Certain land and buildings that have been made by people all over this land are considered as "real estate". After using real estates as a trading good, "the value of the property" concept has been born. "Value of the property" term can be explained as the benefit to be obtained by the owner of the property at the time in the market. Since the transaction aim of the property is not only for commercial but also for residential, the value of the real estates is unstable in the market. It varies according to features and the specialties of the real estate, willingness to buy/sell and so on. As viewed from this side, valuation of the property is a complex problem with many parameters and constraints. The objective of this paper is to present a decision model that estimates the value of a residential property according to its structural and neighborhood features. To achieve this, firstly, the evaluation criteria which are commonly used in the literature to determine the characteristics of the residential property have been identified. Then, judgments of the experts from the residential market are collected. The literature outcomes and expert views have been aggregated and customized according to focused problem. As a result, "criteria pool" that will be used in appraising a given residential property is identified. After structuring the decision model, the next stage is prioritizing the criteria. For this purpose, pairwise comparison judgments of the experts are assessed. The performance values of zones as well as residential properties are received based on expert judgments and objective evaluations. Finally, global rating scores, which can be expressed as estimated values of residential properties, are calculated.
\end{abstract}

Keywords: value of residential property, appraising real estate, evaluation criteria, AHP 


\section{Introduction}

Anticipated benefit of a property that will be obtained by its owner in a given time in the real estate market is expressed as the "value of the property". Various business areas necessitate this value in their special fields. Purchase-sale transactions, insurance transactions, mortgage loans evaluation, inheritance shares, residential purchases with the aim of investment, taxes calculations can be count as examples that need the currency value of the property at a given time. Because of that, valuation needs consistent and systematic process. According to international standards, there are seven steps to determine the value of a given property. These steps are as follows:

1. Defining the scope of a given property

2. Collecting data about the real estate and analyze

3. Defining "the most efficient and the best use" of a given property

4. Determine a land value

5. Implementation of an evaluation method

6. Estimate the final value

7. Preparing an appraisal report

At step 5, evaluation expert needs reliable and widely accepted methods to appraise the value of real estate. There are three commonly used methods of assessment that have been determined in accordance with international standards. They are "peer comparison", "discount cash flow analysis" and "cost approach".

Peer comparison is the most widely used and accepted methods of valuation, that is used by professional experts in the real estate market. Peer comparison approach, takes into account the substitutes of a given property. This approach utilizes the current market value of substitute properties and tries to estimate the value of a subjected property. This method is useful for a region in which it is easy to find peers as well as peer's selling prices. In this method, as the number of peers increase, the valuation of the property which is the subject of valuation gets closer to the true value. Since most of the time it cannot be possible to find an exactly the same peers of a given property, it is better to use price for square meter or "net income multiplier" - a multiplier that can be obtained by dividing the value of selling price to net income - to compare.

Discount cash flow analysis calculates the current time value of expected incomes and expenses of a given property. It is used in lack of finding enough peers in a given zone.

On the other hand, third method, cost approach, considers the costs in the case of the reconstruction of the same property. It takes into account the money should be spent, land costs, reconstruction costs and depreciation values to estimate the value of a given property. Potential downside of this method is misapprehension of the values because of not considering the market fluctuations.

Besides these methods, there are several approaches which seek an appropriate method to estimate the most accurate value of properties. Since the currency value of a property is unstable and cannot be explained just by the features of the building or neighborhood area, valuation of the property can be described as a complex problem with many parameters and constraints. When we focused on the nature of valuation property problem, we come up with three main features which are in accordance with the main characteristics of decision problems: 
1. Property valuation is done under conditions of uncertainty: Valuating a residential property cannot be patterned on peer comparison all the time. The property can be unique in a given zone or can have situation-specific features. So, valuation expert should consider forthcoming features as well as the current structural and environmental factors. While considering these forthcoming features, mostly the interest rates, economic conditions, and environmental factors such as per capita national income is uncertain and appraisal is done under these uncertainty.

2. Assumptions are made in the process of valuation: While evaluating a given property, the market conditions and trends must be analyzed deeply. Although the features that has an impact on currency value of the property has been analyzed, most of the features are assumed to be permanent. As an example, if expert is evaluating a residential building with a forest view and if there is a sign in governmental papers or rumor in the market which assists that the forest will be a construction zone in the immediate future, than expert should also consider and assume this property with and without forest view.

3. Valuation is done with limited circumstances: Defining currency value of the property is time-restricted and it is dependent to attributes of the property at the time of the valuation, the valuation of the expert skills, property holding / selling trends etc.

As it can be inferred from the main features of valuation problem, it is possible to face with contradicted situations and various conflicted features during the valuation process. For example, while a residential property with better features (structural features like better floor quality, more rooms, open pool etc...) assess more than the one with poor qualities in the same zone; it can be assessed less according to one that is with poor features, but a better view in a high rated zone. In order to estimate the most accurate currency value of a given property, real estate valuation expert as a decision maker, should decide the evaluation criteria that he/she is going to take into account while evaluating a given property. He/she is also responsible for deciding on the convenient peers among the substitute candidates and reflecting the unmanageable attributes, as he/she deemed appropriate, to his/her estimation. So, defining the criteria which have an impact on the changings of the currency value must be the first step of our study.

\section{Literature Review}

There are several studies in the literature which seek an appropriate model to appraise the value of the property. Pagourtzi and others have been divided these methods in two groups: "traditional methods" and "advanced methods". Peer comparison method, which has commonly wide usage in the residential market, investment/income method and multiple regression method can be counted as examples of "traditional methods". The models, which simulate the stakeholders' mental model in the market for appraising, are called as an "advanced models". Artificial neural networks, hedonic pricing methods and fuzzy logic models are the examples of advanced models. In the literature, most of the studies which are conducted with appraising of residential property have utilized the hedonic methods. This method is useful for establishing a relationship between the criteria and the value of the property. But before conducting a relationship between criteria and value of the property, it is important to identify and select the criterion which has meaningful effect on valuation process. 
The initial studies in this area began in the mid-1960s. Alonso, 1964, claims that a neighborhood of the trade centers is a key value for defining the value of the property. After Alonso, Muth, 1969, Kain \& Quingley, 1970, Adair et al, 2000, Din et al, 2001, Fan et al, 2006 did research on defining the criteria.

Rossini, 1997, has claimed that, the criteria like transaction value, area, number of rooms, and year of constructions do not contain qualitative characteristics. On the other hand style of the buildings, neighborhood area, common areas of the interest zone are the basic and strong criteria on evaluating property but mostly there is no sufficient information about these types of qualitative criteria.

\section{Objectives}

The main goal of appraisal process is to estimate the most accurate currency value of a given property. To reach this aim, during an evaluation process, expert should cover all features, constraints and possible opportunities/treats which may affect currency value of the property. Since accomplished estimations are based on logic, real estate valuation expert needs a decision model, which incorporates various data he/she collected and provides a logic that coincides with the estimation and real estate market projections. The objective of this research is to identify evaluation criteria which have a modifier effect on currency value of a given property in an abstracted zone and propose a decision model that estimates the value of a residential property according to its identified features.

\section{Methodology}

"Real estate" term corresponds to various types of immovable like residential property, commercial center or agricultural land. Since all types of immovable have its own specialties to be worthy, it is better to focus on valuation process according to a given property's immovable type. For instance, "the yield of soil" can be an evaluation criterion for agricultural land but it has no meaningful effect on residential property valuation process. So for being more specific and clear, in the scope of this research, we will focus on residential properties' valuation. To build up a stabilize decision model for appraising process, first we need to know the criteria which have meaningful effect on the currency value of a given residential property. To identify a "criteria pool", we utilized the previous researches as well as experts' judgments.

Firstly the evaluation criteria which are commonly used in the literature to determine the residential property have been identified. Then, judgments of experts from the residential market are collected. The literature outcomes and expert views have been aggregated and customized according to focused problem.

At first stage, literature review has been conducted. The previous researches that are focused on residential properties valuation process have been observed and the criteria which have been used for valuation have been identified. As a result, we come up with 34 criteria.

At the second stage of the study, real estate valuation experts have taken part in identifying the criteria which have a modifier effect on value of residential properties. Experts who specialized in appraising in 7 big cities in Turkey (Adana, Ankara, Antalya, Bursa, İstanbul, İzmir, Kocaeli) have commented the major factors that have powerful effect on pricing. Consequently, 15 criteria have been determined.

International Symposium of
the Analytic Hierarchy
$\begin{aligned} & \text { Process } \\ & \end{aligned}$


After literature outcomes and expert views have been collected, all criteria have been aggregated to build a final "criteria pool". Since appraisal process is a complex problem with many parameters and constraints, it will be better to break down the problem into constituent small parts and create hierarchical levels to analyze better. For this purpose, to make the appraisal problem more clear, 39 criteria have been grouped under main captures, according to their relevance. As can be seen in Table 1, hierarchical levels have been built.

Table 1: Final criteria pool for appraising

\begin{tabular}{|c|c|c|c|c|}
\hline $\begin{array}{l}\text { Environmental } \\
\text { Characteristics }\end{array}$ & $\begin{array}{l}\text { Physical } \\
\text { Characteristics }\end{array}$ & $\begin{array}{l}\text { Constructive } \\
\text { Characteristics }\end{array}$ & $\begin{array}{l}\text { Enhancing } \\
\text { Characteristics }\end{array}$ & $\begin{array}{l}\text { Market Related } \\
\text { Characteristics }\end{array}$ \\
\hline $\begin{array}{l}\text { Factor of nearness to } \\
\text { trade and shopping } \\
\text { centers** }\end{array}$ & $\begin{array}{l}\text { size of living } \\
\text { area** }\end{array}$ & type of residence & $\begin{array}{l}\text { number of garage } \\
\text { stalls** }\end{array}$ & Days in market \\
\hline $\begin{array}{l}\text { Factor of public } \\
\text { transportation } \\
\text { systems } * *\end{array}$ & Age & construction type & pool** & $\begin{array}{l}\text { favorable financing } \\
\text { term existence }\end{array}$ \\
\hline Location characteristic & number of rooms & heating system** & $\begin{array}{l}\text { number of } \\
\text { fireplaces }\end{array}$ & $\begin{array}{l}\text { similar yearly rent } \\
\text { income* }\end{array}$ \\
\hline Landscape ${ }^{* *}$ & lot size & fuel type* & $\begin{array}{l}\text { presence of central } \\
\text { air }\end{array}$ & \\
\hline $\begin{array}{l}\text { Factor of noise and air } \\
\text { pollutions }\end{array}$ & floor num $* *$ & saloon floor $* *$ & Hydrophone & \\
\hline $\begin{array}{l}\text { Factor of regional } \\
\text { conformity to city } \\
\text { planning criteria }\end{array}$ & view of residence & Bathroom floor & Generator & \\
\hline $\begin{array}{l}\text { Factor of nearness to } \\
\text { cultural centers }\end{array}$ & $\begin{array}{l}\text { number of open } \\
\text { sides }\end{array}$ & water system & Elevator & \\
\hline \multirow[t]{3}{*}{ neighborhood effect } & state of house & $\begin{array}{l}\text { quality of } \\
\text { construction** }\end{array}$ & Security & \\
\hline & Usability & Completion rate* & common areas* & \\
\hline & & material quality $*$ & & \\
\hline
\end{tabular}

Criteria without stars: Evaluation criteria based on literature review

Criteria with *: Evaluation criteria based on real estate valuation expert's judgments

Criteria with **: Evaluation criteria based on both

\section{Conclusion}

As aforementioned, currency value of the residential property cannot be just related with the features of the structure. It is also related with non-construction related factors like contiguity of trading and social centers, market trends and environmental issues. Literature review and experts' judgments exhibits that 39 criteria under 5 main clusters can be used for appraisal process of residential properties. 
The next stage of the study is determining the importance of these criteria by experts from the residential market. Pairwise comparisons, based on AHP method, are made to find out which criterion has more influential effect on the currency value of a given residential property.

After that, performance value of each residential property with respect to 39 criteria will be assessed on AHP rating scales. In order to compute global scores of each property, multiplications of property's individual rating scores and relative importance of related criteria are summed up.

As a final stage, a certain number of properties are selected from a given abstracted zone to constitute sample pool. Then, average selling price of selected properties as well as their average global score are calculated. The relation between average values can be used for forecasting the selling price of the unapprised properties that are in the same abstracted zone.

\section{Key References}

Ahn, J. J., Byun H. W., Oh K. J., Kim T.Y., 2012. "Using ridge regression with genetic algorithm to enhance real estate appraisal forecasting" Expert Systems with Applications $39,8369-8379$.

Kuşan H., Aytekin O., Özdemir İ., 2010. "The use of fuzzy logic in predicting house selling price" Expert Systems with Applications 37, 1808-1813.

Selim H., 2009. "Determinants of house prices in Turkey: Hedonic regression versus artificial neural network" Expert Systems with Applications 36, 2843-2852.

Kiefer H., 2011. "The house price determination process: Rational expectations with a spatial context" Journal of Housing Economics 20, 249-266. 